\title{
Article \\ Glycerol Monocaprylate Modulates Gut Microbiota and Increases Short-Chain Fatty Acids Production without Adverse Effects on Metabolism and Inflammation
}

\author{
Junhui Zhang ${ }^{1,2,3,4,5}\left(\mathbb{D}\right.$, Fengqin Feng ${ }^{1,2,3,4,5}$ and Minjie Zhao ${ }^{1,2,3,4,5, *}$ \\ 1 College of Biosystems Engineering and Food Science, Zhejiang University, Hangzhou 310058, China; \\ zhangjunhui9916@163.com (J.Z.); feng_fengqin@hotmail.com (F.F.) \\ 2 National Engineering Laboratory of Intelligent Food Technology and Equipment, Zhejiang University, \\ Hangzhou 310058, China \\ 3 Key Laboratory for Agro-Products Postharvest Handling of Ministry of Agriculture and Rural Affairs, \\ Zhejiang University, Hangzhou 310058, China \\ 4 Key Laboratory for Agro-Products Nutritional Evaluation of Ministry of Agriculture, Zhejiang University, \\ Hangzhou 310058, China \\ 5 Ningbo Research Institute, Zhejiang University, Ningbo 315100, China \\ * Correspondence: minjiezhao@zju.edu.cn; Tel.: +86-571-88982981
}

Citation: Zhang, J.; Feng, F.; Zhao, M. Glycerol Monocaprylate Modulates Gut Microbiota and Increases Short-Chain Fatty Acids Production without Adverse Effects on Metabolism and Inflammation. Nutrients 2021, 13, 1427. https:// doi.org/10.3390/nu13051427

Academic Editor: Michael Conlon

Received: 4 March 2021

Accepted: 21 April 2021

Published: 23 April 2021

Publisher's Note: MDPI stays neutral with regard to jurisdictional claims in published maps and institutional affiliations.

Copyright: () 2021 by the authors. Licensee MDPI, Basel, Switzerland. This article is an open access article distributed under the terms and conditions of the Creative Commons Attribution (CC BY) license (https:// creativecommons.org/licenses/by/ $4.0 /)$.

\begin{abstract}
Glycerol monocaprylate (GMC) is a glycerol derivative of medium-chain fatty acids (MCFAs) and is widely used as a preservative in food processing. However, GMC and its hydrolytic acid (octylic acid) have antibacterial properties that may affect the physiology and intestinal microecology of the human body. Therefore, in this study, the effects of two different dosages of GMC (150 and $1600 \mathrm{mg} \mathrm{kg}^{-1}$ ) on glucose, lipid metabolism, inflammation, and intestinal microecology of normal diet-fed C57BL/ 6 mice were comprehensively investigated. The obtained results showed that the level of triglycerides (TGs) in the low-dose group down-regulated significantly, and the anti-inflammatory cytokine interleukin 10 (IL-10) significantly increased, while the pro-inflammatory cytokines monocyte chemotactic protein 1 (MCP-1) and interleukin 1beta (IL-1 $\beta$ ) in the high-dose group were significantly decreased. Importantly, GMC promoted the $\alpha$-diversity of gut microbiota in normal-diet-fed mice, regardless of dosages. Additionally, it was found that the low-dose treatment of GMC significantly increased the abundance of Lactobacillus, while the high-dose treatment of GMC significantly increased the abundance of SCFA-producers such as Clostridiales, Lachnospiraceae, and Ruminococcus. Moreover, the content of short-chain fatty acids (SCFAs) was significantly increased by GMC supplementation. Thus, our research provides a novel insight into the effects of GMC on gut microbiota and physiological characteristics.
\end{abstract}

Keywords: glycerol monocaprylate; gut microbiota; short-chain fatty acids; glucose and lipid metabolism; inflammation

\section{Introduction}

Glycerol monocaprylate (GMC) is a common medium-chain fatty acid monoglyceride synthesized by 1:1 caprylic acid and glycerol. Due to its antibacterial properties, GMC is regarded as a new type of non-toxic and highly effective broad-spectrum food preservative by the National Health Commission of the People's Republic of China. Moreover, GMC has excellent emulsifying properties, which are helpful for stabilizing food shape, improving tissue structure, and optimizing product quality [1]. GMC with these effective antibacterial and emulsifying properties has been widely used in a variety of foods, such as wet-fresh noodles, pastry, and meat [2].

MCFAs (e.g., caprylic acid, capric acid, and lauric acid) have distinct metabolic merits, as they can be absorbed into the portal vein through the gut and then transported directly to the liver to be rapidly metabolized and no longer synthesize triglycerides. Importantly, 
in hepatocytes, MCFAs are carried to the mitochondria for $\beta$-oxidation without carnitine transferase dependence $[3,4]$. Consequently, they are not stored and thus have less burden on liver metabolism. Due to their special metabolism characteristics, MCFAs can increase energy consumption and fat oxidation, decrease blood triglycerides, improve lipoprotein metabolism, reduce the weight of patients with hypertriglyceridemia, and prevent obesity [5]. For instance, Li et al. found that caprylic acid fed to mice could lower body weight and decrease the levels of total cholesterol and low-density lipoprotein cholesterol [6]. GMC, as a typical glycerol derivative of MCFAs, could be hydrolyzed to caprylic acid and glycerol by lipase in the intestine. It is known that GMC has a long residence time in the intestinal tract, and both GMC and its hydrolytic acid (octylic acid) have antibacterial properties [7]. Hence, GMC may significantly influence the gut microbiota. Nevertheless, its exact effects on host metabolism are still unclear and need further study.

Recently, accumulating evidence has suggested that gut microbiota and its metabolites could have an important effect as a bridge between the diet and the host and subsequently regulate human health $[8,9]$. For instance, microbes in the intestines can ferment indigestible dietary fibers and resistant starch to produce short-chain fatty acids (SCFAs). SCFAs can regulate immune responses and energy metabolism in vivo by inhibiting histone deacetylases and also activating G protein-coupled receptors [10]. Fushimi et al. reported that intake of dietary acetic acid could promote bile acid excretion, inhibit lipid synthesis in the liver, and reduce the level of serum cholesterol and triglycerides (TG) in cholesterol-fed rats [11]. Kelly et al. demonstrated that the intestinal epithelium absorbs butyrate to correct physiological hypoxia and maintain intestinal barrier function by restoring hypoxia inducible factor expression [12]. Furthermore, intestinal microorganisms play a fundamental role in various physiological activities of the host, such as digestion and absorption of substances, carbohydrate metabolism, fat metabolism, amino acid metabolism, immune regulation, etc. [13]. Thus, maintaining a healthy and stable intestinal microbiome is of great importance.

In our earlier research on glycerol monolaurate (GML), it was found that adding a low-dose of GML (150 mg kg-1) in a normal diet promoted metabolic syndrome, mild inflammation, and dysbiosis of gut microbiota [14]. A further study by Zhao et al. showed that using a high dose of GML (1600 $\mathrm{mg} \mathrm{kg}^{-1}$ ) alleviated high-fat diet-induced metabolic disorders and the dysbiosis of gut microbiota, while reducing levels of serum proinflammatory cytokines [15]. However, it is unclear whether GMC has certain effects on metabolism, inflammation, and gut microbiota. Therefore, in the current study, the effects of low-dose $\left(150 \mathrm{mg} \mathrm{kg}^{-1}\right)$ and high-dose $\left(1600 \mathrm{mg} \mathrm{kg}^{-1}\right)$ GMC on physiology and intestinal microecology in normal-diet-fed mice were extensively investigated. The results demonstrated that the addition of GMC effectively improved the composition and structure of gut microbiota, promoted the abundance of Lactobacillus in the $150 \mathrm{mg} \mathrm{kg}^{-1}$ treated group, and increased the abundance of SCFA-producers such as Clostridiales, Lachnospiraceae, and Ruminococcus in the $1600 \mathrm{mg} \mathrm{kg}^{-1}$ treated group without adverse effects on metabolism and inflammation. Our findings provide a novel insight into the potential mechanisms of GMC's physiological action by demonstrating modulation of gut microbiota populations and activities, including the promotion of microbial diversity and the growth of beneficial bacteria as well as the stimulation of SCFA production.

\section{Materials and Methods}

\subsection{Animals and Diet}

Wild-type male C57BL/ 6 mice (4-5 weeks of age) were purchased from Shanghai SLAC Laboratory Animal Co., Ltd. (Shanghai, China) and then bred and housed at Zhejiang Chinese Medical University Laboratory Animal Research Center (Hangzhou, China) under institutionally approved protocols (Institutional Animal Ethics Committee no. 11164). Mice were maintained at $24^{\circ} \mathrm{C}$ with a $12 \mathrm{~h}$ light/dark cycle, with free access to standard rodent chow diet and water. After a week of acclimatization on a regular diet, mice were divided randomly into three groups ( $n=12$ per group, four mice per cage): (1) NCD, normal chow 
diet (Shanghai Fan Bo Co., Ltd., Shanghai, China) as the control group; (2) GMC150, the normal chow diet incorporating $150 \mathrm{mg} \mathrm{kg}^{-1} \mathrm{GMC}$ as the low-dosage treatment group; (3) GMC1600, the normal chow diet incorporating $1600 \mathrm{mg} \mathrm{kg}^{-1} \mathrm{GMC}$ as the high-dosage treatment group. The diet of the GMC group was made by crushing the control diet and adding the GMC and then pelletizing. The GMC was purchased from Henan Zhengtong Food Technology Co., Ltd. The feeding process took 22 weeks, in which body weight and dietary intake were measured each week. Furthermore, each mouse was placed in a separate metabolic cage and its feces were collected within $2 \mathrm{~min}$ after defecation. Then the fresh fecal was immediately stored at $-80{ }^{\circ} \mathrm{C}$ for downstream analysis. Fecal collection was conducted once a month. After the GMC treatment was completed, the mice fasted for $12 \mathrm{~h}$, and blood was drawn from the intraorbital retrobulbar capillary plexus. Then, mice were euthanized by carbon dioxide inhalation, and the livers, epididymal tissue, and brown fat tissue (BAT) were collected, weighed, and stored at $-80^{\circ} \mathrm{C}$ for downstream analysis.

\subsection{Glucose Metabolism}

At week 20, an intravenous glucose tolerance test was performed as follows: eight randomly selected mice from each group fasted for $12 \mathrm{~h}$ and then were injected intraperitoneally with $2 \mathrm{~g} \mathrm{~kg}^{-1}$ body weight glucose solution. Finally, blood samples were collected from the tail vein at the designated time points $(0,30,60,90$, and $120 \mathrm{~min})$, and the glucose concentrations were measured using an Accu-Check glucometer (Roche Diagnostics Deutschland GmbH, Mannheim, Germany).

Fasting serum glucose concentration was measured with a commercially available kit (Nanjing Jiancheng, Nanjing, China), and fasting serum insulin was measured by a mouse ELISA kit (Wuhan ColorfulGene Biological Technology Co., Ltd., Wuhan, China). Next, the model assessment of insulin resistance homeostasis (HOMA-IR) was computed with the following formula: serum insulin $\left(\mu \mathrm{Mm} \mathrm{L}^{-1}\right) \times$ serum glucose $\left(\mathrm{mmol} \mathrm{L}^{-1}\right) / 22.5$.

\subsection{Biochemical Analysis}

The concentration of serum total cholesterol (T-CHO), triglycerides (TGs), low-density lipoprotein cholesterol (LDL-C), and high-density lipoprotein cholesterol (HDL-C) were quantified by commercially available kits ( $n=12$ per group) from Nanjing Jiancheng Bioengineering Institute, following the respective manufacturer's instructions.

Serum free fatty acid (FFA), leptin (LEP), peptide YY (PYY), adiponectin (ADP), glucagon-like peptide 1 (GLP-1), lipopolysaccharide binding protein (LBP), lipopolysaccharide (LPS), interleukin 10 (IL-10), interleukin 6 (IL-6), interleukin $1 \beta$ (IL-1 $\beta$ ), tumor necrosis factor (TNF), and monocyte chemotactic protein 1 (MCP-1) were measured with an ELISA kit (Wuhan ColorfulGene Biological Technology Co., Ltd., Wuhan, China) under the respective manufacturer's instructions ( $n=8$ per group; serum samples from mice were randomly selected).

\subsection{HEE Staining and Histology Analysis}

After euthanasia, using 10\% buffered formalin fixed mouse liver and epididymal adipose tissue at room temperature for $24 \mathrm{~h}$, the fixed tissue of each mouse ( $n=12$ per group) was embedded in paraffin, sliced at $5 \mu \mathrm{m}$ thickness, and stained with hematoxylin and eosin (H\&E) according to standard protocols. The size and number of stained epididymal fat tissue were analyzed by Image-Pro Plus 6.1 (Media Cybernetics, Inc., Rockville, MD, USA).

\subsection{Gene Expression Analysis by Quantitative Real-Time PCR (qRT-PCR)}

Using TRIzol reagent (Invitrogen, Carlsbad, CA, USA) total RNAs of the liver and brown fat were isolated ( $n=6$ group; samples from mice were randomly selected). cDNA was obtained by reverse transcription of total RNAs with HiScript Reverse Transcription kit (Vazyme, Jiangsu, China). The qPCR was conducted with the $2 \times$ ChamQ SYBR Color qPCR Master Mix (Vazyme Biotech Co., Ltd., Nanjing, China) on a LightCycler 480 system (Roche Applied Science, Indianapolis, IA, USA) with specific mouse primers. Results were 
normalized to the housekeeping YWHAZ gene and calculated based on the $2^{-\Delta \Delta C t}$ method. All the primer sequences are shown in Supplemental Table S1.

\subsection{Western Blot}

Total protein of the liver was extracted with the Tissue Protein Extraction Reagent (Thermo Pierce, Rockford, IL, USA) and quantified with the BCA quantitative kit (Beyotime, Nantong, China). The protein was mixed thoroughly with the loading buffer at the ratio of 1:3 and heated at $100{ }^{\circ} \mathrm{C}$ for $10 \mathrm{~min}$ to denature the protein. The protein was centrifuged at $3000 \mathrm{rpm}$ for $4 \mathrm{~min}$ and separated using 12\% SDS-PAGE gel. It was then transferred onto a PVDF membrane and blocked with $8 \%$ nonfat milk. The membrane was first incubated with primary antibodies against $\beta$-actin (1:10,000 dilution), PPAR $\gamma 2$ (1:1000 dilution), GCK (1:1000 dilution), PPAR $\alpha$ (1:1000 dilution), and FOXO1 (1:1000 dilution) at $4{ }^{\circ} \mathrm{C}$ for $12 \mathrm{~h}$ and then with the secondary antibody for $1 \mathrm{~h}$. The optical density of the strips was analyzed with Image J software, and the values were normalized to $\beta$-actin.

\subsection{Gut Microbiota Analysis with $16 S$ rRNA Gene Sequencing}

Eight mice from each group were randomly selected for 16S rRNA gene sequencing. The total microbial DNA was isolated from weighed feces, which were collected at week 21 using the QIAamp DNA Stool Mini Kit (Qiagen, Dusseldorf, Germany) following the manufacturer's protocols. The bacterial $16 \mathrm{~S}$ rRNA genes, hypervariable regions V3-V4, were amplified with the forward primer and the reverse primer by the thermocycler PCR system (Gene Amp 9700, ABI, Waltham, MA, USA). The amplicons recovered from $2 \%$ agarose gel were purified with AxyPrep DNA Gel Extraction Kit (Axygen Biosciences, Union City, CA, America), quantified by QuantiFluor ${ }^{\mathrm{TM}}$-ST (Promega, Madison, WI, USA), and then paired-end sequenced $(2 \times 300)$ on an Illumina MiSeq platform (Illumina, San Diego, CA, USA) following the standard procedure by Majorbio Bio-Pharm Technology Co. Ltd. (Shanghai, China). Then, raw reads from the original DNA fragments were quality-filtered and merged. Sequences were clustered into the same operational taxonomic units (OTUs) with the UPARSE software package. Then, the sequence was analyzed by the RDP Classifier algorithm against the Greengenes 16S rRNA bacteria database. The species abundance of each sample was counted at the phylum level as well as the family level and studied visually through the histogram visualization method. A heatmap based on the top 30 dominant genera was used to present the Community species composition and species abundance information. Linear discriminant analysis effect size (LEfSe) analysis was performed to analyze the species differences between the groups. Finally, the correlation heatmap was applied to visualize the relationship between different species in the sample and blood biochemical criterion and to evaluate the correlation between microbial classification and the blood biochemical criterion.

\subsection{Short-Chain Fatty Acids (SCFAs) Composition Analysis}

The composition and concentration of SCFAs were quantified from frozen fecal samples using gas chromatography. A total of $50 \mathrm{mg}$ of feces was weighed in a centrifuge tube to which $250 \mu \mathrm{L}$ of ultrapure water was added ( $n=8$ per group; feces from mice were randomly selected). Then the suspension was vortexed for $5 \mathrm{~min}$, and $10 \mu \mathrm{L}$ of $5 \mathrm{~mol} \mathrm{~L}^{-1}$ $\mathrm{HCl}$ was added into the centrifuge tube and vortexed again for $1 \mathrm{~min}$. The suspension was then incubated for $10 \mathrm{~min}$ at room temperature, with intermittent shaking. Prior to chromatographic analysis, the fecal suspension was centrifuged at 12,000 rpm for $20 \mathrm{~min}$. Then, $200 \mu \mathrm{L}$ of supernatant was transferred to a new centrifuge tube and supplemented with 2-ethylbutyric acid to $1 \mathrm{mmol} \mathrm{L}^{-1}$. Afterward, $1 \mu \mathrm{L}$ of injection solution was analyzed using a capillary gas chromatograph (GC-2014, SHIMADZU, Kyoto, Japan) with the column DB-FFAP (J\&W Scientific, Agilent Technologies Inc., Santa Clara, CA, USA). The specific operation parameters were as follows: flame ionization detector, $240{ }^{\circ} \mathrm{C}$; injection port, $200^{\circ} \mathrm{C}$; temperature raising program: $100^{\circ} \mathrm{C}$ for $30 \mathrm{~s}, 8^{\circ} \mathrm{C} \mathrm{min}-1$ until $180^{\circ} \mathrm{C}(1 \mathrm{~min})$, 
$20{ }^{\circ} \mathrm{C} \mathrm{min}-1$ until $200{ }^{\circ} \mathrm{C}$ (15 min); nitrogen, hydrogen, and air flow rate: 20,30 and $300 \mathrm{~mL} \mathrm{~min}^{-1}$, respectively.

\subsection{Statistical Analysis}

The results were expressed as mean \pm SEM, and statistical analysis, as well as the drawing, were performed by GraphPad Prism 6.0 (GraphPad Software Inc., San Diego, CA, USA). Significance among groups was determined using one-way analysis of variance (ANOVA) with Tukey's multiple comparison post-tests. A $p$-value $<0.05$ was considered statistically significant.

\section{Results}

\subsection{Effects of GMC Supplementation on Body Weight, Feed Intake, Adipocyte Size, and}

\section{Liver Histology}

Compared with the NCD group, low-dose treatment and high-dose treatment of GMC had no significant effect on body weight (Figure $1 \mathrm{~A}-\mathrm{C}$ ). There were no significant changes in total feed intake among the NCD and GMC groups (Figure 1D). No obvious differences were observed in the relative weight of epididymal adipose tissues among different groups. However, the relative brown adipose tissue (BAT) weight to body weight ratio at $150 \mathrm{mg} \mathrm{kg}^{-1}$ and $1600 \mathrm{mg} \mathrm{kg}^{-1}$ GMC supplementation showed a significant decrease compared to the NCD group ( $p=0.0280$ and $p=0.0161$, respectively, Figure 1E). Consistent with the result of the relative weight of epididymal adipose, the frequency of $950-9500 \mu \mathrm{m}^{2}$ of stained fat droplets and the size of epididymal adipocyte had no significant differences between the NCD and GMC groups (Figure 1F-I). Furthermore, no abnormalities were found in the H\&E histology of the liver tissues (Supplemental Figure S1A-C).
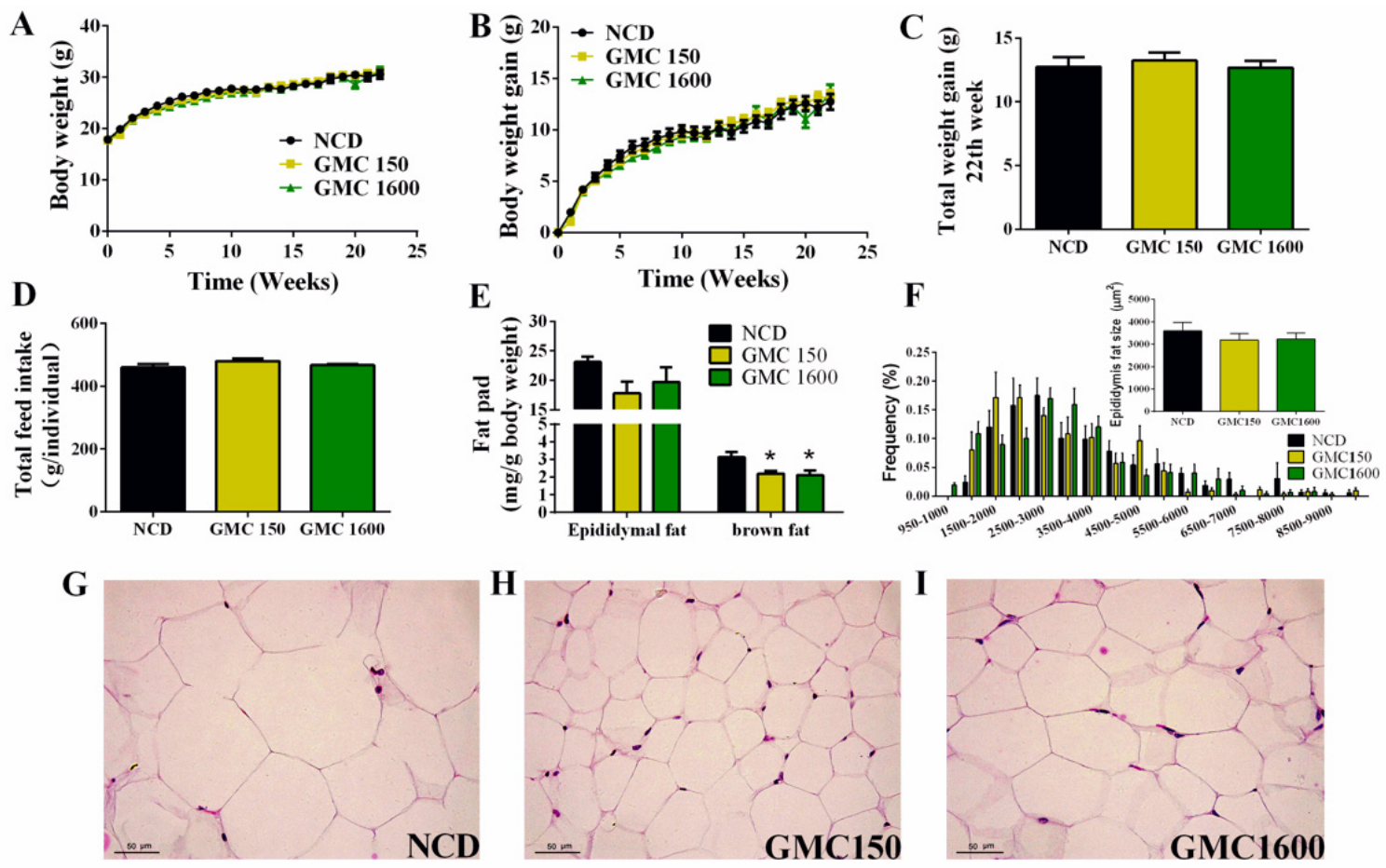

Figure 1. Effects of GMC treatment on (A) original body weight change in each group, (B) body weight gain, (C) total weight gain in the 22nd week, (D) total feed intake, and (E) the relative weight of epididymal fat pad and brown fat tissue of mice. (F-I) Epididymal adipocyte size and frequency calculated by H\&E staining and estimated with the Image-Pro software $(200 \times)$. Data are expressed as mean $\pm \mathrm{SEM}, n=12\left({ }^{*} p<0.05\right.$ vs. NCD). 


\subsection{Effects of GMC Supplementation on Glucose and Lipid Metabolism}

Low-dose treatment of GMC statistically reduced the level of serum TG when compared with the NCD group and $1600 \mathrm{mg} \mathrm{kg}^{-1} \mathrm{GMC}$ supplementation group $(p=0.0146$ and $p=0.0255$, respectively, Figure 2A). Referring to the content of T-CHO and FFA in the serum, no obvious differences were found among various groups (Figure 2B,C). Markedly, adding $1600 \mathrm{mg} \mathrm{kg}^{-1}$ GMC into the diet significantly decreased the content of HDL-C in comparison to the NCD group ( $p<0.001$, Figure 2D). In contrast, the concentration of LDL-C in the $150 \mathrm{mg} \mathrm{kg}^{-1}$ GMC group was significantly up-regulated when compared with the NCD group ( $p=0.0167$, Figure 2E). Furthermore, both the $150 \mathrm{mg} \mathrm{kg}^{-1}$ GMC and $1600 \mathrm{mg} \mathrm{kg}^{-1} \mathrm{GMC}$ supplementation resulted in a marked decline in the ratio of HDL-C to LDL-C in contrast with the NCD group $(p<0.001, p=0.0053$, respectively, Figure 2F). To evaluate the influence of different dosages of GMC supplementation on glucose metabolism, an intraperitoneal glucose tolerance test (IGTT) was conducted. There was no detectable change observed in the blood glucose curve and the area under the curve (AUC) among different groups (Figure 2G,H). In addition, $1600 \mathrm{mg} \mathrm{kg}^{-1}$ GMC supplementation resulted in a decreasing tendency in the concentration of serum fasting insulin compared to the NCD group ( $p=0.0977$, Figure 2I). Meanwhile, the $1600 \mathrm{mg} \mathrm{kg}^{-1}$ GMC treatment significantly increased the level of serum fasting glucose in comparison with $150 \mathrm{mg} \mathrm{kg}^{-1}$ GMC treatment ( $p=0.0362$, Figure 2J). The HOMA-IR of the GMC and NCD groups showed no obvious differences (Figure 2K).
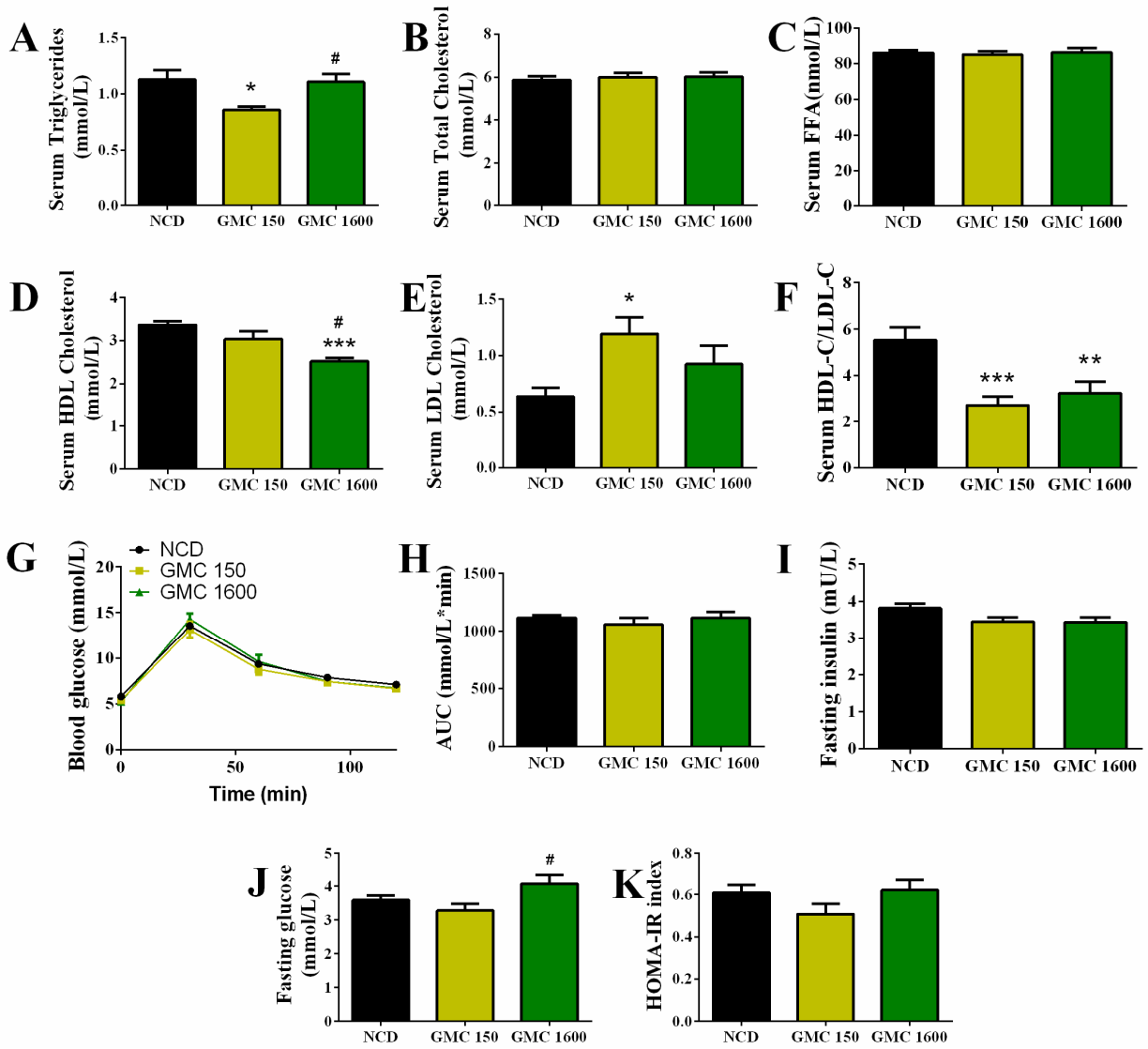

Figure 2. Changes in the glucose and lipid metabolism. (A) Triglyceride (TG), (B) Total cholesterol (T-CHO), (C) Free fatty acid (FFA), (D) High-density lipoprotein cholesterol (HDL-C), (E) Lowdensity lipoprotein cholesterol (LDL-C), (F) the ratio of HDL-C to LDL-C, (G) glucose tolerance test (IGTT), (H) area under the curve (AUC) of IGTT, (I) fasting insulin, (J) fasting glucose, and (K) HOMA-IR. Data are expressed as mean $\pm \mathrm{SEM}, n=8-12\left({ }^{*} p<0.05 \mathrm{vs.} \mathrm{NCD,}{ }^{* *} p<0.01 \mathrm{vs.} \mathrm{NCD,}\right.$ *** $p<0.001$ vs. NCD, $\# p<0.05$ vs. GMC150). 


\subsection{Effects of GMC Supplementation on Appetite-Hormone Level and Inflammation-Related Cytokines in Serum}

Adding $150 \mathrm{mg} \mathrm{kg}^{-1} \mathrm{GMC}$ into the diet significantly reduced the concentration of the serum GLP-1 ( $p=0.0128$, Figure 3A). Interestingly, the $1600 \mathrm{mg} \mathrm{kg}^{-1} \mathrm{GMC}$ treatment had an obvious down-regulation in the concentration of LEP compared to the NCD group and low-dose treatment group ( $p=0.0013$ and $p=0.0135$, respectively). However, there were no significant differences in serum ADP, PYY, LPS, LBP, TNF, and IL-6 among different groups (Figure 3C-H). Importantly, the content of serum IL-10 had a significant up-regulation after the low-dose treatment of GMC ( $p=0.0111$, Figure 3I). In contrast with the NCD group and $150 \mathrm{mg} \mathrm{kg}^{-1}$ GMC treated group, the concentration of serum MCP-1 in the $1600 \mathrm{mg} \mathrm{kg}^{-1}$ GMC group had an obvious down-regulation $(p=0.0182$ and $p=0.0050$, respectively, Figure 3J). Moreover, the level of serum IL-1 $\beta$ in the $1600 \mathrm{mg} \mathrm{kg}^{-1} \mathrm{GMC}$ group decreased compared with the NCD group ( $p=0.0601$, Figure $3 \mathrm{~K})$.
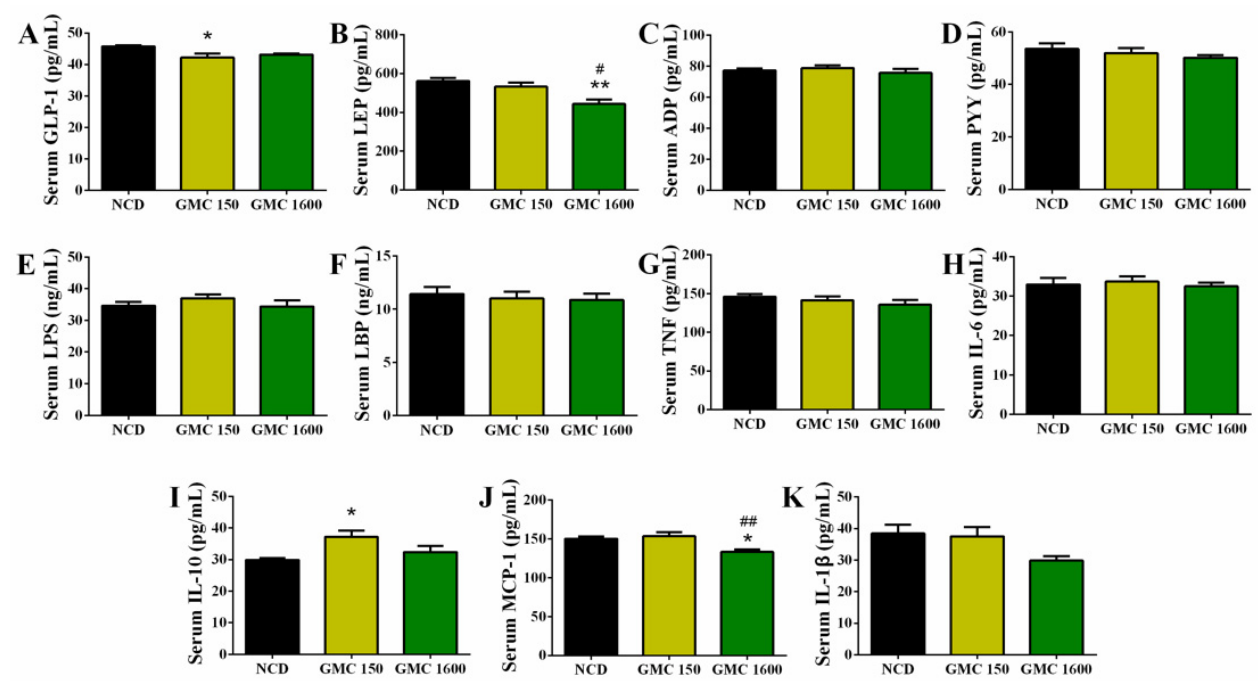

Figure 3. Changes in serum hormone levels and inflammation-related cytokines. (A) Glucagon-like peptide 1 (GLP-1), (B) Leptin (LEP), (C) Adiponectin (ADP), (D) Peptide YY (PYY), (E) Lipopolysaccharide (LPS), (F) Lipopolysaccharide binding protein (LBP), (G) Tumor necrosis factor (TNF), (H) Interleukin 6 (IL-6), (I) Interleukin 10 (IL-10), (J) Monocyte chemotactic protein 1 (MCP-1), and (K) Interleukin $1 \beta$ (IL-1 $\beta)$. Data are expressed as mean \pm SEM, $n=8(* p<0.05$ vs. NCD, ** $p<0.01$ vs. NCD, \# $p<0.05$ vs. GMC150, \#\# $p<0.01$ vs. GMC150).

\subsection{Effects of GMC Supplementation on the Expressions of Genes and Proteins Related with Glucose and Lipid Metabolism and Inflammation}

The mRNA and protein expression of PPAR $\alpha$ was significantly increased by $150 \mathrm{mg} \mathrm{kg}^{-1}$ GMC treatment compared with the NCD group ( $p=0.0483$, Figure 4A and $p<0.0001$, Figure 4E). Interestingly, the expression of ACOX1, which is the target gene of PPAR $\alpha$, also up-regulated in the $150 \mathrm{mg} \mathrm{kg}^{-1} \mathrm{GMC}$ treated group ( $p=0.0323$, Figure $\left.4 \mathrm{~A}\right)$. Moreover, an obvious up-regulation of the mRNA and protein expression of PPAR $\gamma 2$ was observed when adding $1600 \mathrm{mg} \mathrm{kg}^{-1} \mathrm{GMC}$ into the diet ( $p=0.0019$, Figure 4A and $p<0.0001$, Figure 4E). Meanwhile, CD36, which is the target gene of PPAR $\gamma 2$, also had a higher expression in the $1600 \mathrm{mg} \mathrm{kg}^{-1}$ GMC group ( $p=0.0253$, Figure $4 \mathrm{~A}$ ). However, there were no significant changes in the expression of FASN, SCD1, CYP7A1, SREBP-1C, and FGF21 in different groups (Figure 4A). The mRNA level of HMGCR under the $1600 \mathrm{mg} \mathrm{kg}^{-1} \mathrm{GMC}$ treatment was higher than that in the low-dose treatment group $(p=0.0367$, Figure $4 \mathrm{~A})$. Interestingly, G6PC and PEPCK, which are associated with the glucose metabolism, significantly upregulated in the $150 \mathrm{mg} \mathrm{kg}^{-1} \mathrm{GMC}$ treatment group $(p=0.0105$ and $p=0.0427$, respectively, Figure $4 \mathrm{~B})$. The mRNA and protein expression of GCK were significantly increased in the $1600 \mathrm{mg} \mathrm{kg}^{-1}$ GMC group $(p=0.0487$, Figure $4 \mathrm{~B}$ and $p<0.0001$, Figure $4 \mathrm{E})$. Moreover, the expression of CHREBP and its target gene LPK were significantly increased by $1600 \mathrm{mg} \mathrm{kg}^{-1}$ 
GMC treatment ( $p=0.0178$ and $p=0.0267$, respectively, Figure 4B). Interestingly, the protein expression of FOXO1 significantly increased after GMC treatment $(p<0.001$ and $p=0.0469$, respectively, Figure 4E). Furthermore, inflammation-related genes, including TLR2, TNF, and MCP-1, had a down-regulation in the GMC-treated groups (Figure 4C). Notably, the expression of PRDM16, which is associated with the thermogenesis of brown fat tissue (BAT), was significantly increased in the $1600 \mathrm{mg} \mathrm{kg}^{-1}$ GMC group ( $p=0.0451$, Figure 4D). The expression of UCP1 had no significant changes in the different groups (Figure 4D).
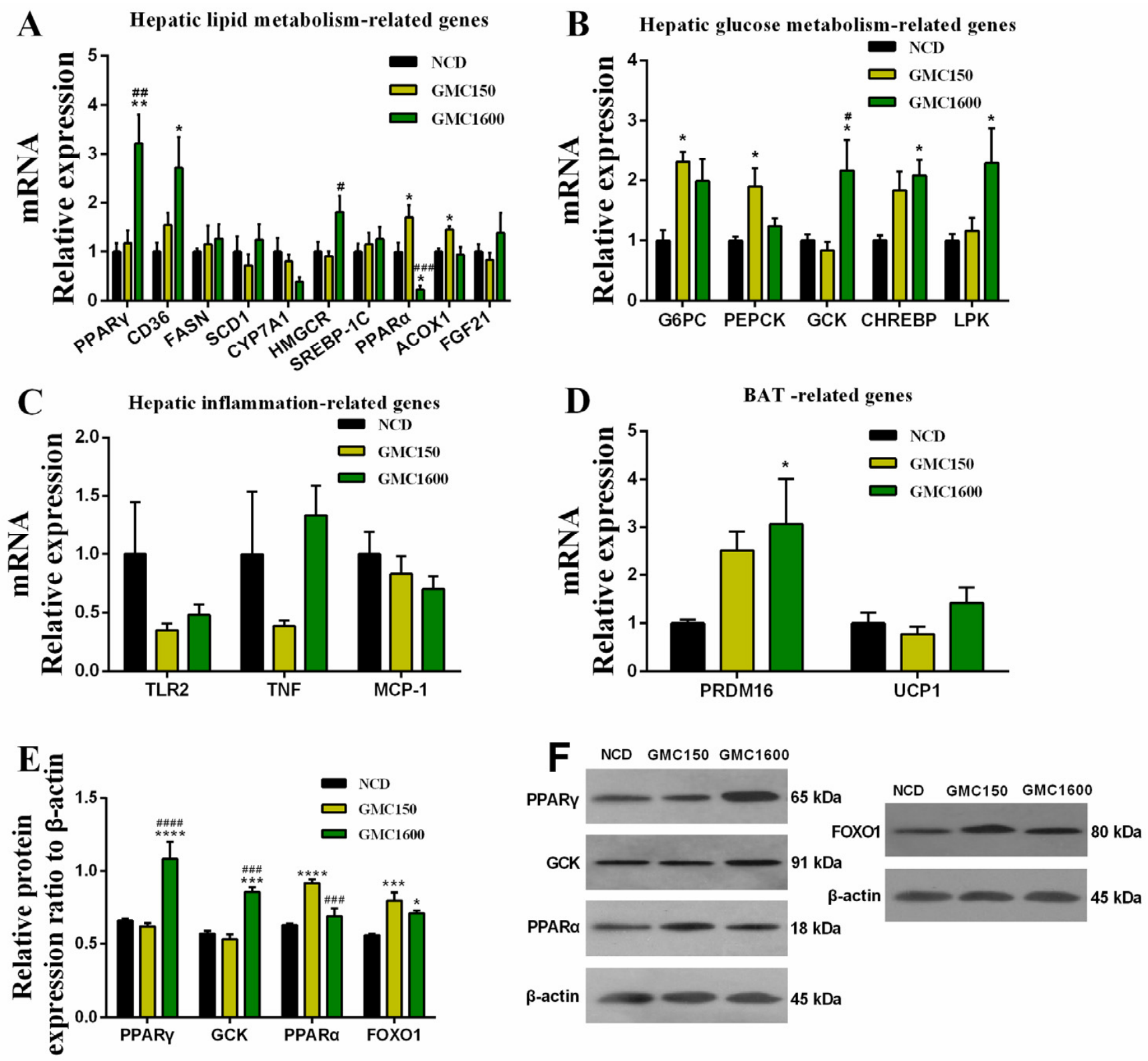

Figure 4. Changes in the expressions of genes and protein related with glucose and lipid metabolism and inflammation. (A) Hepatic lipid metabolism-related genes: PPAR $\gamma 2$, CD36, FASN, SCD1, CYP7A1, HMGCR, SREBP-1C, PPAR $\alpha$, ACOX1, and FGF21; (B) hepatic glucose metabolism-related genes: G6PC, PEPCK, GCK, CHREBP, and LPK; (C) hepatic inflammationrelated genes: TLR2, TNF, and MCP-1; (D) BAT-related genes: PRDM16 and UCP1; (E,F) relative expression of the liver:

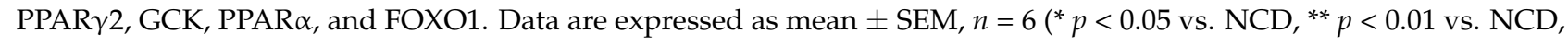
${ }^{* * *} p<0.001$ versus NCD, ${ }^{* * * *} p<0.0001$ vs. NCD, \# $p<0.05$ vs. GMC150, \#\# $p<0.01$ vs. GMC150, \#\#\# $p<0.001$ vs. GMC150, \#\#\# $p<0.0001$ vs. GMC150). 


\subsection{Effects of GMC Supplementation on the Diversity and Composition of Gut Microbiota}

For $\alpha$-diversity analysis, the number of observed species in the $150 \mathrm{mg} \mathrm{kg}^{-1} \mathrm{GMC}$ group was higher than in the NCD group (Figure 5A). Additionally, the Chao index and the Ace index were significantly increased by $150 \mathrm{mg} \mathrm{kg}^{-1}$ GMC treatment $(p=0.0074$ and $p=0.0181$, respectively, Figure 5B,C). Importantly, $1600 \mathrm{mg} \mathrm{kg}^{-1} \mathrm{GMC}$ presented an obvious up-regulation in observed species, the Chao index, and the Ace index $(p=0.0178$, $p=0.0313$, and $p=0.0483$, respectively) as well as an obvious down-regulation in Simpson index compared with the NCD group ( $p=0.0101$, Figure $5 \mathrm{~A}-\mathrm{E}$ ). The results of the coverage index indicated that the real situation of microbes in the samples was reflected (Figure 5F). Interestingly, 785, 872, and 856 bacterial OTUs were obtained in the NCD, $150 \mathrm{mg} \mathrm{kg}{ }^{-1}$, and $1600 \mathrm{mg} \mathrm{kg}^{-1}$ GMC groups, respectively, whereas 33, 75, and 58 OTUs were found in the three groups, respectively (Figure 5G). The principal coordinates analysis (PCoA), which is based on unweighted UniFrac, indicated that different dosages of GMC kept microbial composition away from the NCD group, which explained $14.68 \%$ of the total variance observed in PC1 (Figure 5H). In PC2, which explained $12.58 \%$ of the total variance, the gut microbiota in the NCD group separated from the $150 \mathrm{mg} \mathrm{kg}^{-1} \mathrm{GMC}$ group but not from the $1600 \mathrm{mg} \mathrm{kg}^{-1}$ GMC group (Figure $5 \mathrm{H}$ ). The analysis at the phylum level suggested that the gut microbiota in fecal samples was dominated by Firmicutes, Bacteroidetes, Actinobacteria, and Proteobacteria. Moreover, the $150 \mathrm{mg} \mathrm{kg}^{-1}$ GMC group showed that the relative abundance of Firmicutes increased while the relative abundance of Bacteroidetes decreased compared to the NCD group (Figure 5I). At the family level, there was a down-regulation in the abundance of S24-7 and an up-regulation in the abundance of Lactobacillaceae as a result of the $150 \mathrm{mg} \mathrm{kg}^{-1} \mathrm{GMC}$ treatment. In contrast with the NCD group, the $1600 \mathrm{mg} \mathrm{kg}^{-1}$ GMC treatment group had lower levels of the abundance of Erysipelotrichaceae and higher levels of the abundance of family Clostridiales (Figure 5J).

\subsection{Gut Microbiota Composition at Genus Level and Correlation Analysis of Blood Biochemical Criterion}

The relative abundance of the 30 most dominant genera in the three groups was analyzed. The results indicated that supplementing the diet with $150 \mathrm{mg} \mathrm{kg}^{-1}$ GMC significantly increased the level of Lactobacillus compared with the NCD group and the $1600 \mathrm{mg} \mathrm{kg}^{-1} \mathrm{GMC}$ treatment group $(p=0.0096$ and $p=0.0451$, respectively, Figure $6 \mathrm{~A}, \mathrm{~B})$. Importantly, the addition of $1600 \mathrm{mg} \mathrm{kg}^{-1}$ GMC markedly increased the abundance of Clostridiales, Lachnospiraceae, and Ruminococcus compared to the NCD group $(p=0.0210$, $p=0.0254$, and $p=0.0443$, respectively, Figure 6A,C-E) and had a higher relative abundance in Turicibacter and Prevotella than that in NCD group (Figure 6F,G). Changes in Akkermansia were also analyzed despite not being one of the 30 most abundant genera. Interestingly, the relative abundance of Akkermansia increased in the $1600 \mathrm{mg} \mathrm{kg}^{-1}$ GMC group (Figure $6 \mathrm{H}$ ). Linear discriminant analysis effect size (LEfSe) comparison analysis was conducted to evaluate various dosages of GMC on the composition of gut microbiota (Figure 6I). The results indicated that class Bacilli, order Lactobacillales, family Lactobacillaceae, and Lactobacillus were dominant bacteria in $150 \mathrm{mg} \mathrm{kg}^{-1} \mathrm{GMC}$ treatment group, and family Lachnospiraceae as well as order Clostridiales were advantage bacteria in the $1600 \mathrm{mg} \mathrm{kg}^{-1}$ GMC treatment group. In the NCD group, the domain bacteria were class Actinobacteria, order Bifidobacteriales, family Bifidobacteriaceae, and Bifidobacterium. The correlation between blood biochemical criterion and gut microbiota at the genus level was performed by Spearman's correlation analysis (Figure 6J). Lactobacillus showed a strong positive correlation with LDL-C and strong negative correlations with TG as well as the ratio of HDL-C to LDL-C. Bifidobacterium was positively correlated with LEP, IL-1 $\beta$, and HDL-C, while Lachnospiraceae was negatively correlated with LEP. Interestingly, Rikenellaceae had strong positive correlations with serum glucose and HOMA-IR. 


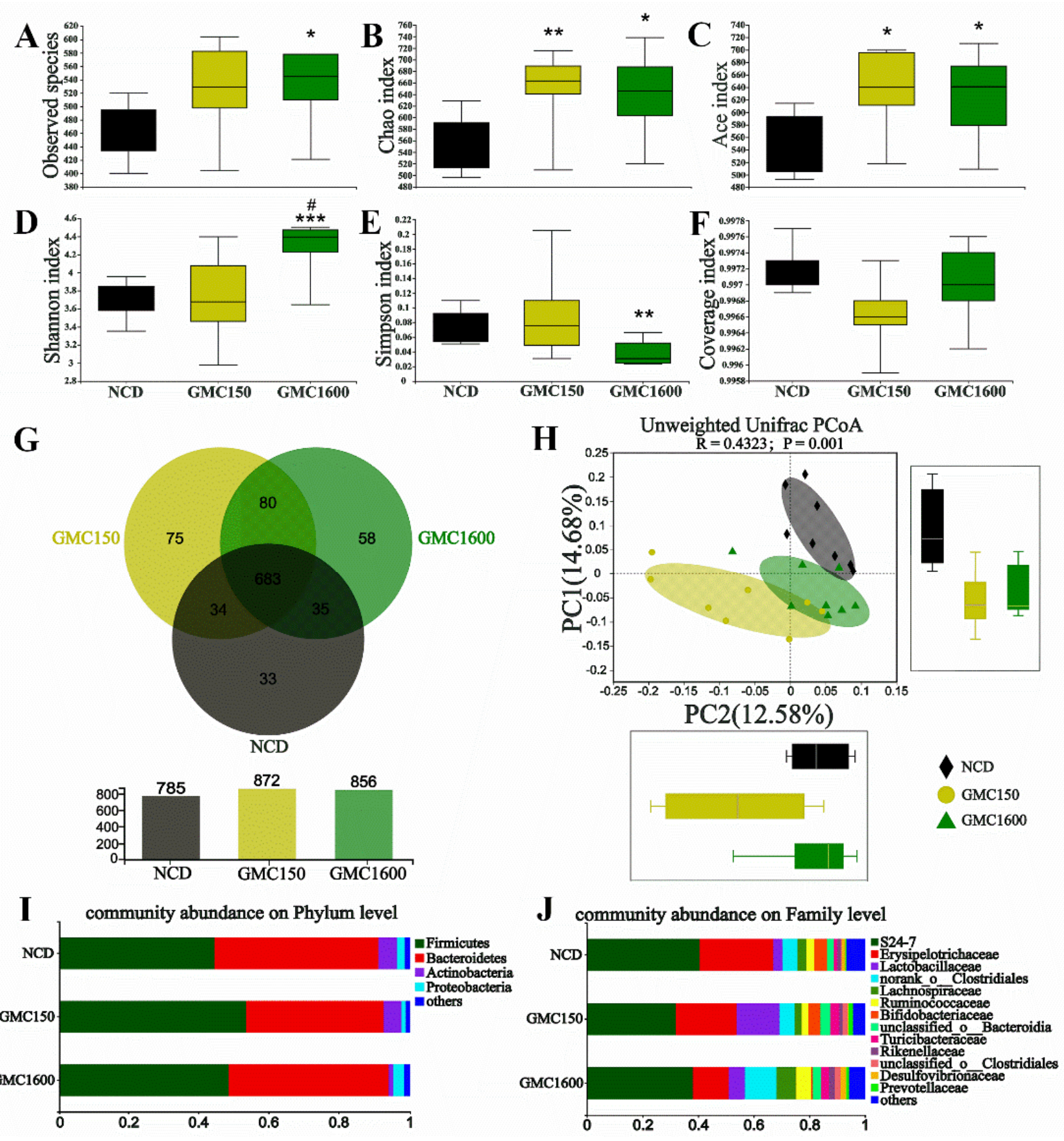

Figure 5. GMC supplementation altered the structure of intestinal microbiota. $\alpha$-diversity: (A) observed species, (B) Chao index, (C) Ace index, (D) Shannon index, (E) Simpson index, (F) Coverage index, and (G) OTU Venn diagram between treatments; $\beta$-diversity: (H) PCoA plot based on unweighted UniFrac distances. Relative abundance of gut microbiota at the phylum level (I) and at family level (J). Data are expressed as mean \pm SEM, $n=8\left({ }^{*} p<0.05\right.$ vs. NCD, ${ }^{* *} p<0.01$ vs. NCD, *** $p<0.001$ vs. NCD, \# $p<0.05$ vs. GMC150). 
A
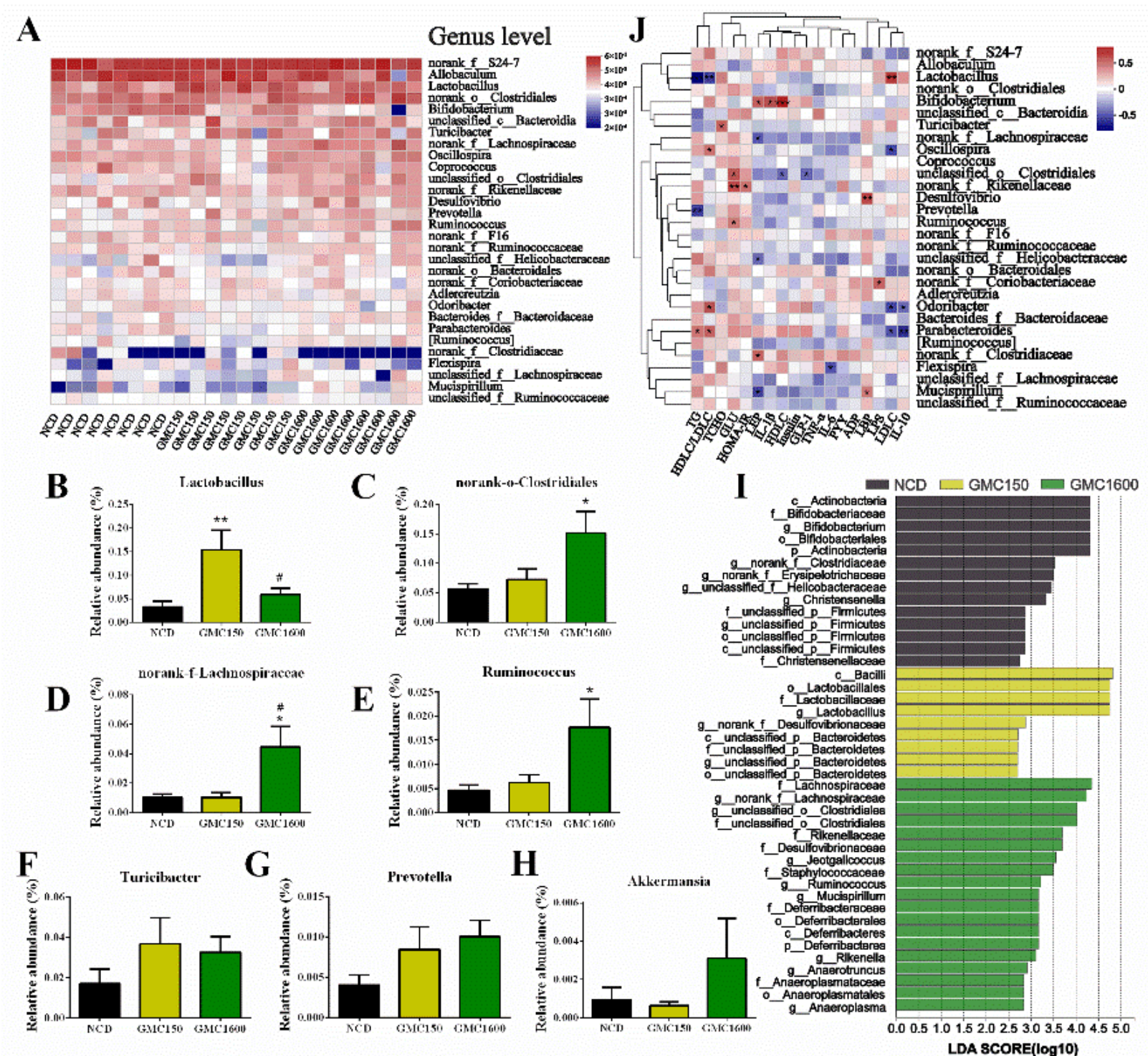

Figure 6. GMC supplementation changed the composition of intestinal microbiota. (A) A heat map of the relative abundance of the 30 most abundant genera among different treatments. The relative abundances of (B) Lactobacillus, (C) Clostridiales, (D) Lachnospiraceae, (E) Ruminococcus, (F) Turicibacter, (G) Prevotella, and (H) Akkermansia (not in top 30 genera). (I) LEfSe analysis among all the experimental groups (Log LDA > 2.0). (J) The correlation between the gut microbiota and blood biochemical criterion. Data are expressed as mean $\pm \mathrm{SEM}, n=8$ (* $p<0.05$ vs. NCD, ${ }^{* *} p<0.01$ vs. NCD, \# $p<0.05$ vs. GMC150).

\subsection{GMC Supplementation Increased the Content of SCFAs in Feces}

The concentration of SCFAs is shown in Figure 7. Supplementation of $150 \mathrm{mg} \mathrm{kg}^{-1}$ GMC resulted in obvious increases in most SCFAs compared to the NCD group, including acetic acid, propionic acid, isobutyric acid, hexanoic acid, and total SCFAs $(p<0.05)$. Similarly, the $1600 \mathrm{mg} \mathrm{kg}^{-1}$ GMC treatment group, in comparison with the NCD group, showed significantly increases in the contents of propionic acid, isobutyric acid, isovaleric acid, and hexanoic acid $(p<0.05)$. 


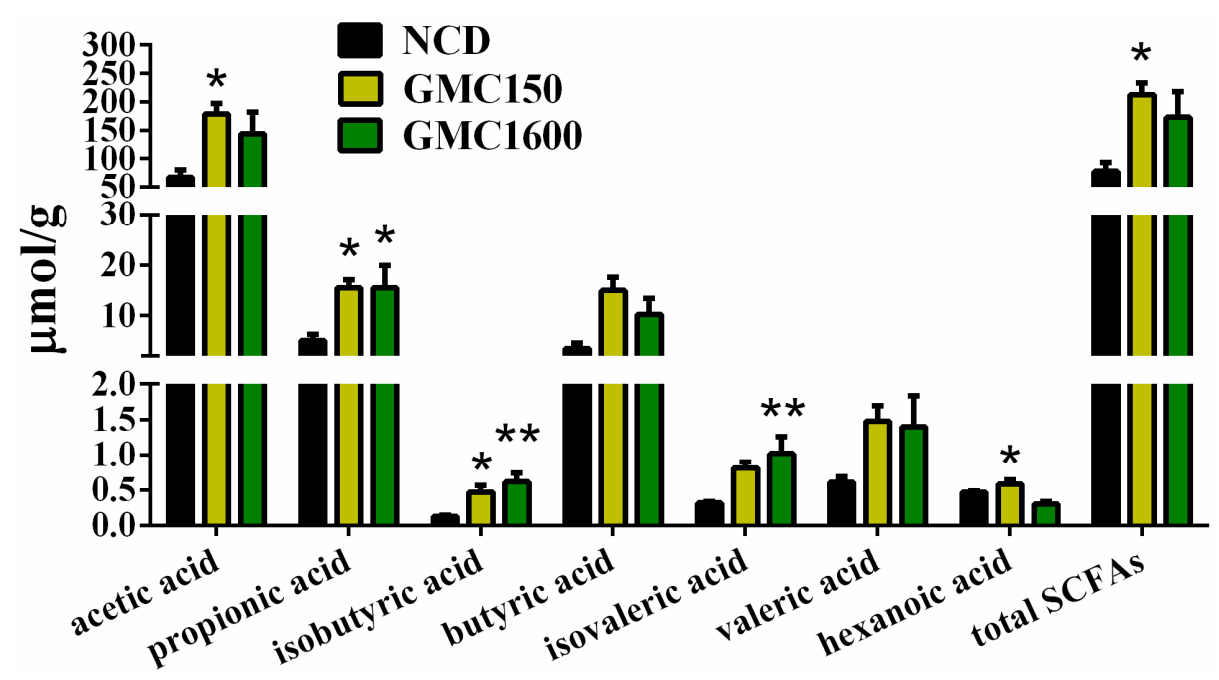

Figure 7. The concentrations of fecal SCFAs (acetic acid, propionic acid, isobutyric acid, butyric acid, isovaleric acid, valeric acid, hexanoic acid, and total SCFAs). Data are expressed as mean \pm SEM, $n=8{ }^{*} p<0.05$ versus NCD, ${ }^{* *} p<0.01$ versus NCD).

\section{Discussion}

There is growing evidence that medium-chain fatty acid glyceride-based food additives can modulate the gut microbiota in mice and affect their health [14-18]. Originally, GMC was a medium-chain fatty acid glyceride food preservative. However, further studies are needed to clarify the specific effects of GMC on intestinal microbiota and host health. In the present research, we aimed to provide more practical and useful information on the application of GMC as a food preservative by studying its effect on C57BL/ 6 male mice with a normal diet.

Notably, we found that GMC supplementation significantly decreased the relative weight of brown fat tissue and had a decrease in the relative weight of epididymal adipose and the size of epididymal adipocytes without affecting the body weight and feed intake. Interestingly, it is reported that medium-chain-triglyceride-fed rats had lighter fat pads [19]. In addition, we observed that the mice treated with $150 \mathrm{mg} \mathrm{kg}^{-1} \mathrm{GMC}$ had a lower concentration of serum TG. These data collectively suggest that lipid metabolism in mice was affected by the intake of GMC. This could be explained by the fact that MCFAs are readily oxidized in the liver and lead to greater energy expenditure, thus resulting in decreased size of fat depots [20]. As members of the nuclear receptor superfamily, the roles of the peroxisome proliferator-activated receptors (PPARs: PPAR $\alpha, \operatorname{PPAR} \beta / \delta$, and PPAR $\gamma$ ) in metabolic homeostasis were identified [21]. PPAR $\alpha$ is known to modulate the expression of genes involved in the $\beta$-oxidation of fatty acids $[22,23]$, such as its secondary target gene ACOX1, which is a rate-limiting enzyme in the $\beta$-oxidation of fatty acid $[24,25]$. Meanwhile, several studies have suggested that PPAR $\alpha$ may increase fatty acid metabolism in the liver [26-28]. Here, our data showed that PPAR $\alpha$ and ACOX1 expression was significantly up-regulated at a low dose in GMC-treated mice. Indeed, the decreased TG levels in mice were confirmed to be associated with the up-regulation of PPAR $\alpha$ [29]. These data collectively imply that $150 \mathrm{mg} \mathrm{kg}^{-1}$ GMC might increase the metabolism of fatty acids. $\operatorname{PPAR} \gamma$, is also expressed in the liver, despite being predominantly expressed in adipose [30]. Previous studies have demonstrated that the increased expression of PPAR $\gamma$ in adipose tissue is responsible for fat accumulation [31]. In contrast, other studies have shown that decreased lipids in the liver are associated with up-regulation of PPAR $\gamma[30,32]$. Therefore, more research may be needed on such a controversial point. CD36 is transcriptionally regulated by PPAR $\gamma$ and also plays a role in regulating fatty acids metabolism [33]. Here, an evident up-regulation of PPAR $\gamma 2$ and CD36 was observed after $1600 \mathrm{mg} \mathrm{kg}^{-1}$ GMC treatment. This may be consistent with the reduction of the lipid by the GMC treatment. HMGCR is a rate-limiting enzyme in the synthesis of cholesterol by hepatocytes [34]. 
Here, we showed that HMGCR was up-regulated and consistent with the decline in the ratio of HDL-C to LDL-C after GMC high-dose treatment, which reminds us that the effect of GMC on lipid metabolism needs further study. Moreover, PRDM16, which is a transcriptional regulator in the differentiation of brown adipocyte, had a significantly higher expression in the $1600 \mathrm{mg} \mathrm{kg}^{-1} \mathrm{GMC}$ group [35]. Meanwhile, UCP1, the regulatory gene of BAT-thermogenesis, also had a slightly increased level in the high-dose GMC treatment group [36]. These data indicate that $1600 \mathrm{mg} \mathrm{kg}^{-1} \mathrm{GMC}$ may have a positive effect on stimulating the differentiation and thermogenesis of brown fat.

Disturbed homeostasis of glucose metabolism is one of the dominant features of metabolic syndrome and has a high risk for the development of some metabolic diseases, such as obesity and type 2 diabetes [37,38]. Thus, it is important to evaluate the effect of GMC on glucose metabolism. G6PC and PEPCK are two key gluconeogenic enzymes in hepatocytes, highly activated during fasting and suppressed in the fed state by insulin [39]. The up-regulation of G6PC and PEPCK in the low-dose GMC treatment group was in line with the significantly increased protein expression of FOXO1, which plays a vital role in mediating the effects of insulin on glucose metabolism [40]. Moreover, serum insulin decreased slightly with $150 \mathrm{mg} \mathrm{kg}^{-1} \mathrm{GMC}$ treatment, consistent with the obvious down-regulation of GLP-1, which is known to potentiate insulin secretion [41]. These data suggest that $150 \mathrm{mg} \mathrm{kg}^{-1} \mathrm{GMC}$ may play a regulatory role in glucose homeostasis through gluconeogenesis. CHREBP is one of the major transcription factors that regulate carbohydrate metabolism; LPK, which is the target gene of CHREBP, also plays an important role in glycolysis [42]. Similarly, GCK, which is the key factor in glycolysis, can also regulate insulin secretion and glucose metabolism of the liver, and loss of its activity can lead to diabetes [43]. We speculated that $1600 \mathrm{mg} \mathrm{kg}^{-1} \mathrm{GMC}$ may have an effect on glycolysis to regulate glucose metabolism. Referring to the above results, the supplementation of GMC had no adverse effects on glucose metabolism in mice, and these findings are similar with our previous study [16].

TLR2, which belongs to pattern-recognition receptors, is regarded as the major cause of sustaining inflammation [44]. The expression of TNF, as well as MCP-1, also plays a crucial role in inflammatory response. Here, the mRNA levels of TLR2, TNF, and MCP-1 were decreased by GMC treatment. In addition, evidence suggests that the infiltration of mouse macrophages in the liver is mainly controlled by MCP-1, whereas IL-10 regulated the inflammatory response by inhibiting the release of inflammatory mediators by mononuclear macrophages $[45,46]$. In our study, we observed that the serum content of pro-inflammatory cytokines MCP-1 and IL-1 $\beta$ was decreased in the $1600 \mathrm{mg} \mathrm{kg}^{-1}$ GMC group in comparison with the NCD group, whereas the anti-inflammatory cytokine IL-10 had a significant increase in the $150 \mathrm{mg} \mathrm{kg}^{-1}$ GMC group. Given the effect of GMC on the inflammatory response, we hypothesized that GMC might have the potential to improve inflammation.

Accumulated research has revealed that intestinal microbiota composition and structure play crucial roles in host health and are associated with a variety of diseases [47]. Intestinal microbes interact with their hosts and depend on each other. In other words, the host can provide nutrients for gut microbes, which in turn help the host digest dietary fiber to produce SCFAs [48]. In the present study, we found that the $\alpha$-diversity of gut microbiota significantly increased after GMC treatment. Moreover, the Venn diagram demonstrated that OTUs in the GMC supplementation groups increased. Recent research performed by Nishida et al. revealed that the decreased diversity of gut microbiota plays a vital role in the occurrence of inflammatory bowel disease [49]. Hence, increased diversity may be a desired health benefit as it maintains gut microbiota balance. Additionally, the $\beta$-diversity indicated that the samples in the GMC group were clustering intensively and gradually away from the NCD group, which suggested communities of gut microbiota altered by GMC treatment in a particular direction. Recently, growing evidence has suggested that the abundance of Firmicutes in the intestine decreases, and the abundance of Bacteroidetes increases, in some patients with severe diseases such as sepsis, cirrhosis, and Alzheimer's disease [50-52]. In support of this, $\mathrm{Xu}$ et al. considered that disease severity had negative 
correlations with Firmicutes, Clostridia, and Ruminococcaceae abundances [53]. Zhao et al. also found that there was an increase in the abundance of Firmicutes and a decrease in the abundance of Bacteroidetes after GML treatment [15]. Moreover, it has been identified that Akkermansia has positive effects on host health [54]. In our research, the abundance of Firmicutes was increased, while the abundance of Bacteroidetes was decreased, in the $150 \mathrm{mg} \mathrm{kg}^{-1}$ GMC group. Additionally, the abundance of Clostridiales and Ruminococcus significantly increased under $1600 \mathrm{mg} \mathrm{kg}^{-1} \mathrm{GMC}$ treatment and the abundance of Akkermansia also saw an increase. These results together suggest that the addition of GMC may contribute to the maintenance of host health. Lactobacillus, as a recognized probiotic, is increasingly used in food and medicine to balance the disturbed intestinal microbiota and related gastrointestinal dysfunction [55-57]. Notably, the significantly increased abundance of Lactobacillus in the low-dose group also suggests the benefits of GMC to host health, which is consistent with our previous study on GML [15]. Moreover, with a GMC treatment of $1600 \mathrm{mg} \mathrm{kg}^{-1}$, SCFA producers (Clostridiales, Lachnospiraceae, and Ruminococcus) were significantly increased, while Prevotella and Turicibacter were slightly increased. These bacteria are major producers of butyrate, which can increase the amount and enhance the function of regulatory T cells [58-61]. The rise of SCFA producers was consistent with our observations of the significantly increased SCFAs extracted from feces in GMC groups. It is universally acknowledged that SCFAs are the mediator of the interaction between intestinal microbiota and host metabolism and are associated with host health $[48,62]$. The increase of acetic acid may be one of the reasons for the TG decline in the $150 \mathrm{mg} \mathrm{kg}^{-1}$ treatment [11]. A review that summarized current studies on the effects of SCFAs on human health indicated that SCFAs can enter the systemic circulation to affect surrounding tissues, improve blood glucose and insulin sensitivity, and have the function of preventing obesity and related diseases [63]. Notably, it was observed that the two doses of GMC had the same effect of on the content of SCFAs. We speculated that the low dose of GMC would have a significant effect on gut microbes, in particular stimulating the production of SCFAs by certain gut microbiota. Thus, with the increase of GMC concentration, the content of SCFAs did not result in more significant changes. Collectively, in our research, the increased abundance of SCFA producers and the consequent increase in the concentration of SCFAs showed that the addition of GMC may play a crucial role in maintaining the health of the host and may alleviate the occurrence of certain diseases.

\section{Conclusions}

The present study indicated that GMC supplementation significantly modulated the gut microbiota composition and significantly increased the abundance of SCFA producers, resulting in the rise of SCFA content. Furthermore, most of the metabolism-related indicators and inflammatory cytokines were not adversely regulated by GMC. The current study comprehensively assessed the impacts of GMC on host health from multiple perspectives, such as intestinal microecology, glucose and lipid metabolism, and inflammation, providing a new scientific basis for the application of GMC in the food industry.

Supplementary Materials: The following are available online at https:/ / www.mdpi.com/article/10 $.3390 /$ nu13051427/s1, Figure S1: H\&E staining of liver in each group, Table S1: Primer sequences used for qRT-PCR analysis.

Author Contributions: Conceptualization, J.Z. and M.Z.; methodology, F.F.; software, J.Z.; validation, M.Z. and F.F.; formal analysis, J.Z.; investigation, J.Z.; resources, J.Z.; data curation, M.Z.; writingoriginal draft preparation, J.Z.; writing—review and editing, M.Z.; visualization, M.Z.; supervision, F.F.; project administration, F.F.; funding acquisition, F.F. and M.Z. All authors have read and agreed to the published version of the manuscript.

Funding: This research was funded by the National Natural Science Foundation of China, grant numbers 32072224, 32001693 and 31972079 . Research was also funded by the Natural Science Foundation of Zhejiang Province, grant numbers LD19C200001, LQ21C200007 and LY18C200006. 
Institutional Review Board Statement: The study was conducted according to the guidelines of the Declaration of Helsinki and approved by the Institutional Review Board of Zhejiang Chinese Medical University Laboratory Animal Research Center (protocol code No. 11164 and approved on 21 October 2019).

Informed Consent Statement: Not applicable.

Data Availability Statement: Data described in the manuscript will be provided on reasonable request to the corresponding author.

Conflicts of Interest: The authors declare no conflict of interest.

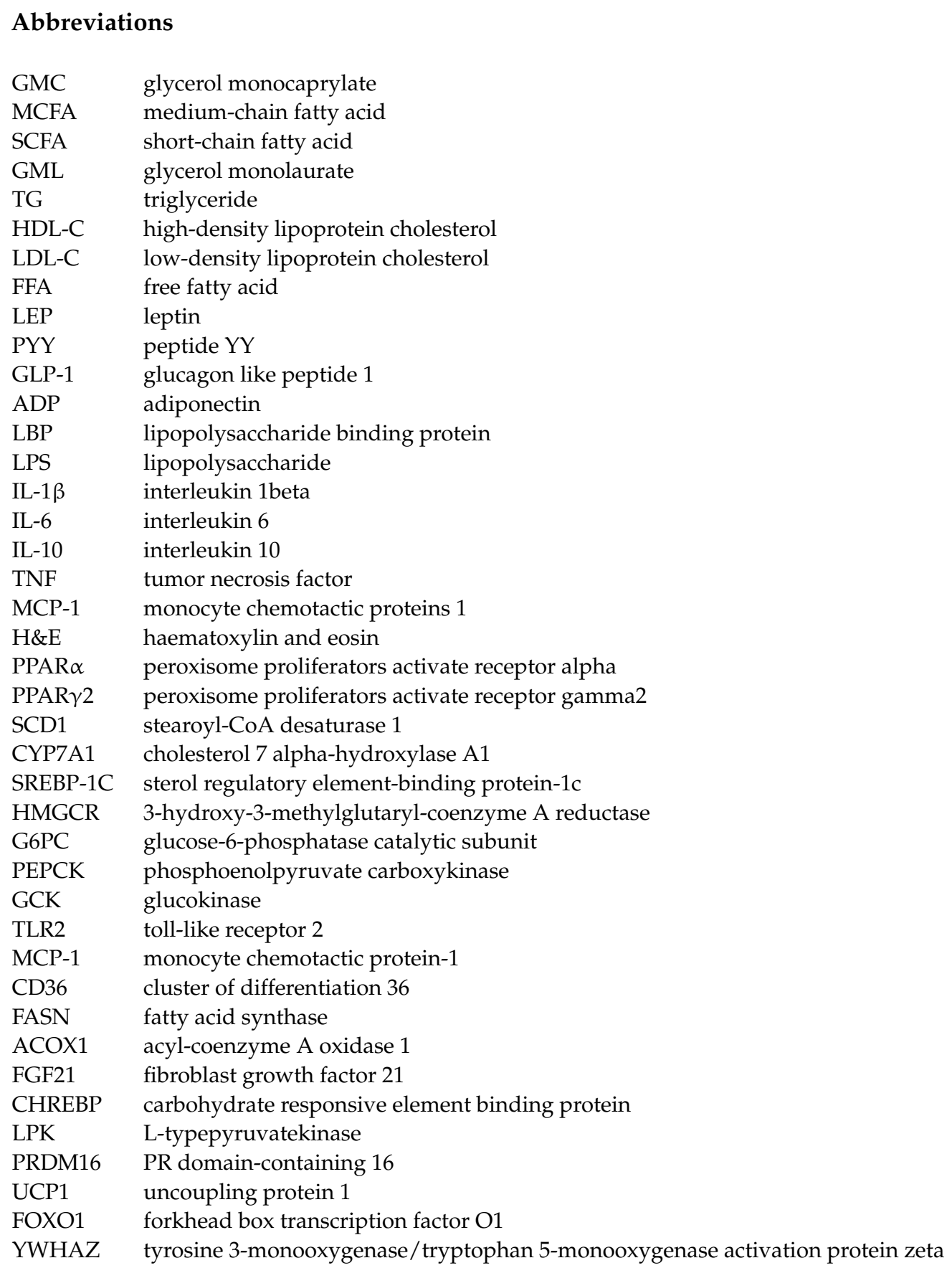




\section{References}

1. Pantoja-Romero, W.S.; Estrada-Lopez, E.D.; Picciani, P.H.S.; Oliveira, O.N.; Lachter, E.R.; Pimentel, A.S. Efficient molecular packing of glycerol monostearate in Langmuir monolayers at the air-water interface. Colloid Surf. A Physicochem. Eng. Asp. 2016, 508, 85-92. [CrossRef]

2. Ge, H.; Zang, Y.; Cao, Z.; Ye, X.; Chen, J. Rheological properties, textural and compound preservative of kelp recombination noodles. LWT Food Sci. Technol. 2020, 118, 108729. [CrossRef]

3. Briscoe, C.P.; Tadayyon, M.; Andrews, J.L.; Benson, W.G.; Chambers, J.K.; Eilert, M.M.; Ellis, C.; Elshourbagy, N.A.; Goetz, A.S.; Minnick, D.T.; et al. The orphan G protein-coupled receptor GPR40 is activated by medium and long chain fatty acids. J. Biol. Chem. 2003, 278, 11303-11311. [CrossRef]

4. Gulick, T.; Cresci, S.; Caira, T.; Moore, D.D.; Kelly, D.P. The peroxisome proliferator-activated receptor regulates mitochondrial fatty acid oxidative enzyme gene expression. Proc. Natl. Acad. Sci. USA 1994, 91, 11012-11016. [CrossRef] [PubMed]

5. Peter, S.; Lech, W. Short- and medium-chain fatty acids in energy metabolism: The cellular perspective. J. Lipid Res. 2016, 57, 943-954.

6. Li, H.; Liu, Y.; Zhang, X.; Xu, Q.; Zhang, Y.; Xue, C.; Guo, C. Medium-chain fatty acids decrease serum cholesterol via reduction of intestinal bile acid reabsorption in C57BL/6J mice. Nutr. Metab. 2018, 15, 37. [CrossRef] [PubMed]

7. Yuan, T.; Geng, Z.; Dai, X.; Zhang, X.; Wei, W.; Wang, X.; Jin, Q. Triacylglycerol containing medium-chain fatty acids: Comparison of human milk and infant formulas on lipolysis during in vitro digestion. J. Agric. Food Chem. 2020, 68, 4187-4195. [CrossRef] [PubMed]

8. Nicholson, J.K.; Holmes, E.; Kinross, J.; Burcelin, R.; Gibson, G.; Jia, W.; Pettersson, S. Host-gut microbiota metabolic interactions. Science 2012, 336, 1262-1267. [CrossRef] [PubMed]

9. Lozupone, C.A.; Stombaugh, J.I.; Gordon, J.I.; Jansson, J.K.; Knight, R. Diversity, stability and resilience of the human gut microbiota. Nature 2012, 489, 220-230. [CrossRef] [PubMed]

10. Koh, A.; De Vadder, F.; Kovatcheva-Datchary, P.; Fredrik, B. From dietary fiber to host physiology: Short-chain fatty acids as key bacterial metabolites. Cell 2016, 165, 1332-1345. [CrossRef] [PubMed]

11. Fushimi, T.; Suruga, K.; Oshima, Y.; Fukiharu, M.; Tsukamoto, Y.; Goda, T. Dietary acetic acid reduces serum cholesterol and triacylglycerols in rats feda cholesterol-rich diet. Br. J. Nutr. 2006, 95, 916-924. [CrossRef] [PubMed]

12. Kelly, C.J.; Zheng, L.; Campbell, E.L.; Saeedi, B.; Scholz, C.C.; Bayless, A.J.; Wilson, K.E.; Glover, L.E.; Kominsky, D.J.; Magnuson, A.; et al. Crosstalk between microbiota-derived short-chain fatty acids and intestinal epithelial HIF augments tissue barrier function. Cell Host Microbe 2015, 17, 662-671. [CrossRef] [PubMed]

13. Clemente, J.C.; Ursell, L.K.; Parfrey, L.W.; Knight, R. The impact of the gut microbiota on human health: An integrative view. Cell 2012, 148, 1258-1270. [CrossRef]

14. Jiang, Z.; Zhao, M.; Zhang, H.; Li, Y.; Liu, M.; Feng, F. Antimicrobial emulsifier-glycerol monolaurate induces metabolic syndrome, gut microbiota dysbiosis, and systemic low-grade inflammation in low-fat diet fed mice. Mol. Nutr. Food Res. 2018, 62, 1700547. [CrossRef] [PubMed]

15. Zhao, M.; Jiang, Z.; Cai, H.; Li, Y.; Mo, Q.; Deng, L.; Zhong, H.; Liu, T.; Zhang, H.; Kang, J.X.; et al. Modulation of the gut microbiota during high-dose glycerol monolaurate-mediated amelioration of obesity in mice fed a high-fat diet. mBio 2020, 11, e00190-20. [CrossRef]

16. Mo, Q.; Fu, A.; Deng, L.; Zhao, M.; Li, Y.; Zhang, H.; Feng, F. High-dose glycerol monolaurate up-regulated beneficial indigenous microbiota without inducing metabolic dysfunction and systemic inflammation: New insights into its antimicrobial potential. Nutrients 2019, 11, 1981. [CrossRef] [PubMed]

17. Zhao, M.; Cai, H.; Jiang, Z.; Li, Y.; Zhong, H.; Zhang, H.; Feng, F. Glycerol-monolaurate-mediated attenuation of metabolic syndrome is associated with the modulation of gut microbiota in high-fat-diet-fed mice. Mol. Nutr. Food Res. 2019, 63, 1801417. [CrossRef] [PubMed]

18. Liu, T.; Tang, J.; Feng, F. Medium-chain alpha-monoglycerides improves productive performance and egg quality in aged hens associated with gut microbiota modulation. Poult. Sci. 2020, 99, 7122-7132. [CrossRef] [PubMed]

19. Han, J.; Hamilton, J.A.; Kirkland, J.L.; Corkey, B.E.; Guo, W. Medium-chain oil reduces fat mass and down-regulates expression of adipogenic genes in rats. Obes. Res. 2003, 11, 734-744. [CrossRef]

20. St-Onge, M.P.; Jones, P.J.H. Physiological effects of medium-chain triglycerides: Potential agents in the prevention of obesity (Reprinted from vol 132, pg 329, 2002). J. Nutr. 2002, 132, 329-332. [CrossRef] [PubMed]

21. Wu, L.W.; Li, J.J.; Feng, J.; Ji, J.; Yu, Q.; Li, Y.; Zheng, Y.Y.; Dai, W.Q.; Wu, J.Y.; Guo, C.Y. Crosstalk between PPARs and gut microbiota in NAFLD. Biomed. Pharmacother. 2021, 136, 8. [CrossRef] [PubMed]

22. Aoyama, T.; Peters, J.M.; Iritani, N.; Nakajima, T.; Furihata, K.; Hashimoto, T.; Gonzalez, F.J. Altered constitutive expression of fatty acid-metabolizing enzymes in mice lacking the peroxisome proliferator-activated receptor alpha (PPAR alpha). J. Biol. Chem. 1998, 273, 5678-5684. [CrossRef]

23. Braissant, O.; Foufelle, F.; Scotto, C.; Dauca, M.; Wahli, W. Differential expression of peroxisome proliferator-activated receptors (PPARs): Tissue distribution of PPAR-alpha, -beta, and -gamma in the adult rat. Endocrinology 1996, 137, 354-366. [CrossRef] [PubMed] 
24. Liu, L.; Liu, C.; Zhao, M.; Zhang, Q.; Lu, Y.; Liu, P.; Yang, H.; Yang, J.; Chen, X.; Yao, Y. The pharmacodynamic and differential gene expression analysis of PPAR alpha/delta agonist GFT505 in CDAHFD-induced NASH model. PLoS ONE 2020, 15, e243911. [CrossRef] [PubMed]

25. Sharma, R.S.; Harrison, D.J.; Kisielewski, D.; Cassidy, D.M.; McNeilly, A.D.; Gallagher, J.R.; Walsh, S.V.; Honda, T.; McCrimmon, R.J.; Dinkova-Kostova, A.T.; et al. Experimental Nonalcoholic Steatohepatitis and Liver Fibrosis Are Ameliorated by Pharmacologic Activation of Nrf2 (NF-E2 p45-Related Factor 2). Cell. Mol. Gastroenterol. Hepatol. 2018, 5, 367-398. [CrossRef] [PubMed]

26. Ip, E.; Farrell, G.C.; Robertson, G.; Hall, P.; Kirsch, R.; Leclercq, I. Central role of PPAR alpha-dependent hepatic lipid turnover in dietary steatohepatitis in mice. Hepatology 2003, 38, 123-132. [CrossRef]

27. Ip, E.; Farrell, G.; Hall, P.; Robertson, G.; Leclercq, I. Administration of the potent PPAR alpha agonist, Wy-14,643, reverses nutritional fibrosis and steatohepatitis in mice. Hepatology 2004, 39, 1286-1296. [CrossRef]

28. Svegliati-Baroni, G.; Candelaresi, C.; Saccomanno, S.; Ferretti, G.; Bachetti, T.; Marzioni, M.; De Minicis, S.; Nobili, L.; Salzano, R.; Omenetti, A.; et al. A model of insulin resistance and nonalcoholic steatohepatitis in rats-Role of peroxisome proliferator-activated receptor-alpha and n-3 polyunsaturated fatty acid treatment on liver injury. Am. J. Pathol. 2006, 169, 846-860. [CrossRef]

29. Rakhshandehroo, M.; Knoch, B.; Müller, M.; Kersten, S. Peroxisome proliferator-activated receptor alpha target genes. PPAR Res. 2010, 2010, 20. [CrossRef] [PubMed]

30. Chechi, K.; Yasui, N.; Ikeda, K.; Yamori, Y.; Cheema, S.K. Flax oil-mediated activation of PPAR-gamma correlates with reduction of hepatic lipid accumulation in obese spontaneously hypertensive/NDmcr-cp rats, a model of the metabolic syndrome. $\mathrm{Br}$. $\mathrm{J}$. Nutr. 2010, 104, 1313-1321. [CrossRef] [PubMed]

31. Tontonoz, P.; Nagy, L.; Alvarez, J.G.A.; Thomazy, V.A.; MEvans, R. PPAR gamma promotes monocyte/macrophage differentiation and uptake of oxidized LDL. Cell 1998, 93, 241-252. [CrossRef]

32. Memon, R.A.; Tecott, L.H.; Nonogaki, K.; Beigneux, A.; Moser, A.H.; Grunfeld, C.; Feingold, K.R. Up-regulation of peroxisome proliferator-activated receptors (PPAR-alpha) and PPAR-gamma messenger ribonucleic acid expression in the liver in murine obesity: Troglitazone induces expression of PPAR-gamma-responsive adipose tissue-specific genes in the liver of obese diabetic mice. Endocrinology 2000, 141, 4021-4031. [PubMed]

33. Wupper, S.; Fischer, A.; Luersen, K.; Lucius, R.; Okamoto, H.; Ishida, Y.; Terao, K.; Rimbach, G. High Dietary Kuding Tea Extract Supplementation Induces Hepatic Xenobiotic-Metabolizing Enzymes-A 6-Week Feeding Study in Mice. Nutrients 2020, 12, 40. [CrossRef] [PubMed]

34. Cho, A.-S.; Jeon, S.-M.; Kim, M.-J.; Yeo, J.; Seo, S.-I.; Choi, M.-S.; Lee, M.-K. Chlorogenic acid exhibits anti-obesity property and improves lipid metabolism in high-fat diet-induced-obese mice. Food Chem. Toxicol. 2010, 48, 937-943. [CrossRef] [PubMed]

35. Hao, M.J.; Guan, Z.J.; Gao, Y.; Xing, J.L.; Zhou, X.X.; Wang, C.Y.; Xu, J.; Li, W.M. Huang-Qi San ameliorates hyperlipidemia with obesity rats via activating brown adipocytes and converting white adipocytes into brown-like adipocytes. Phytomedicine 2020, 78, 10. [CrossRef] [PubMed]

36. Fan, H.; Zhang, Y.J.; Zhang, J.; Yao, Q.Y.; Song, Y.F.; Shen, Q.W.; Lin, J.; Gao, Y.X.; Wang, X.Y.; Zhang, L.; et al. Cold-Inducible Klf9 Regulates Thermogenesis of Brown and Beige Fat. Diabetes 2020, 69, 2603-2618. [CrossRef]

37. Mihaylova, M.M.; Vasquez, D.S.; Ravnskjaer, K.; Denechaud, P.-D.; Yu, R.T.; Alvarez, J.G.; Downes, M.; Evans, R.M.; Montminy, M.; Shaw, R.J. Class IIa histone deacetylases are hormone-activated regulators of FOXO and mammalian glucose homeostasis. Cell 2011, 145, 607-621. [CrossRef] [PubMed]

38. Asghar, Z.A.; Cusumano, A.; Yan, Z.; Remedi, M.S.; Moley, K.H. Reduced islet function contributes to impaired glucose homeostasis in fructose-fed mice. Am. J. Physiol. Endocrinol. Metab. 2017, 312, E109-E116. [CrossRef] [PubMed]

39. Puigserver, P.; Rhee, J.; Donovan, J.; Walkey, C.J.; Yoon, J.C.; Oriente, F.; Kitamura, Y.; Altomonte, J.; Dong, H.; Accili, D.; et al. Insulin-regulated hepatic gluconeogenesis through FOXO1-PGC-1 alpha interaction. Nature 2003, 423, 550-555. [CrossRef]

40. Unterman, T.G. Regulation of Hepatic Glucose Metabolism by FoxO Proteins, an Integrated Approach. Curr. Top Dev. Biol. 2018, 127, 119-147. [PubMed]

41. Kuhre, R.E.; Gribble, F.M.; Hartmann, B.; Reimann, F.; Windelov, J.A.; Rehfeld, J.F.; Holst, J.J. Fructose stimulates GLP-1 but not GIP secretion in mice, rats, and humans. Am. J. Physiol. Gastroint. Liver Physiol. 2014, 306, G622-G630. [CrossRef]

42. Shi, J.H.; Lu, J.Y.; Chen, H.Y.; Wei, C.C.; Xu, X.F.; Li, H.; Bai, Q.F.; Xia, F.Z.; Lam, S.M.; Zhang, H.; et al. Liver ChREBP Protects Against Fructose-Induced Glycogenic Hepatotoxicity by Regulating L-Type Pyruvate Kinase. Diabetes 2020, 69, 591-602. [CrossRef] [PubMed]

43. Ma, Y.; Luo, Y.; Gong, S.; Zhou, X.; Li, Y.; Liu, W.; Zhang, S.; Cai, X.; Ren, Q.; Zhou, L.; et al. Low-Frequency Genetic Variant in the Hepatic Glucokinase Gene Is Associated With Type 2 Diabetes and Insulin Resistance in Chinese Population. Diabetes 2021, 70 , 809-816. [CrossRef]

44. Wu, H.; Zhao, C.; Xie, Q.; Xu, J.; Fei, G. TLR2-melatonin feedback loop regulates the activation of NLRP3 inflammasome in murine allergic airway inflammation. Front. Immunol. 2020, 11, 172. [CrossRef] [PubMed]

45. Baeck, C.; Wehr, A.; Karlmark, K.R.; Heymann, F.; Vucur, M.; Gassler, N.; Huss, S.; Klussmann, S.; Eulberg, D.; Luedde, T.; et al. Pharmacological inhibition of the chemokine CCL2 (MCP-1) diminishes liver macrophage infiltration and steatohepatitis in chronic hepatic injury. Gut 2012, 61, 416-426. [CrossRef] [PubMed]

46. Steidler, L.; Hans, W.; Schotte, L.; Neirynck, S.; Obermeier, F.; Falk, W.; Fiers, W.; Remaut, E. Treatment of murine colitis by Lactococcus lactis secreting interleukin-10. Science 2000, 289, 1352-1355. [CrossRef] [PubMed] 
47. Sekirov, I.; Russell, S.L.; Antunes, L.C.M.; Finlay, B.B. Gut microbiota in health and disease. Physiol. Rev. 2010, 90, 859-904. [CrossRef] [PubMed]

48. Serino, M. SCFAs-the thin microbial metabolic line between good and bad. Nat. Rev. Endocrinol. 2019, 15, 318-319. [CrossRef]

49. Nishida, A.; Inoue, R.; Inatomi, O.; Bamba, S.; Naito, Y.; Andoh, A. Gut microbiota in the pathogenesis of inflammatory bowel disease. Clin. J. Gastroenterol. 2018, 11, 1-10. [CrossRef]

50. Liu, Z.; Li, N.; Fang, H.; Chen, X.; Guo, Y.; Gong, S.; Niu, M.; Zhou, H.; Jiang, Y.; Chang, P.; et al. Enteric dysbiosis is associated with sepsis in patients. FASEB J. 2019, 33, 12299-12310. [CrossRef] [PubMed]

51. Bajaj, J.S.; Vargas, H.E.; Reddy, K.R.; Lai, J.C.; O’Leary, J.G.; Tandon, P.; Wong, F.; Mitrani, R.; White, M.B.; Kelly, M.; et al. Association between intestinal microbiota collected at hospital admission and outcomes of patients with cirrhosis. Clin. Gastroenterol. Hepatol. 2019, 17, 756-765. [CrossRef] [PubMed]

52. Vogt, N.M.; Kerby, R.L.; Dill-McFarland, K.A.; Harding, S.J.; Merluzzi, A.P.; Johnson, S.C.; Carlsson, C.M.; Asthana, S.; Zetterberg, H.; Blennow, K.; et al. Gut microbiome alterations in Alzheimer's disease. Sci. Rep. 2017, 7, 13537. [CrossRef]

53. Xu, R.; Tan, C.; He, Y.; Wu, Q.; Wang, H.; Yin, J. Dysbiosis of gut microbiota and short-chain fatty acids in encephalitis: A Chinese pilot study. Front. Immunol. 2020, 11, 1994. [CrossRef]

54. Ansaldo, E.; Slayden, L.C.; Ching, K.L.; Koch, M.A.; Wolf, N.K.; Plichta, D.R.; Brown, E.M.; Graham, D.B.; Xavier, R.J.; Moon, J.J.; et al. Akkermansia muciniphila induces intestinal adaptive immune responses during homeostasis. Science 2019, 364, 1179. [CrossRef]

55. Madsen, K.L.; Doyle, J.S.; Jewell, L.D.; Tavernini, M.M.; Fedorak, R.N. Lactobacillus species prevents colitis in interleukin 10 gene-deficient mice. Gastroenterology 1999, 116, 1107-1114. [CrossRef]

56. Kailasapathy, K.; Chin, J. Survival and therapeutic potential of probiotic organisms with reference to Lactobacillus acidophilus and Bifidobacterium spp. Immunol. Cell Biol. 2000, 78, 80-88. [CrossRef] [PubMed]

57. Zhong, H.; Abdullah; Deng, L.; Zhao, M.; Tang, J.; Liu, T.; Zhang, H.; Feng, F. Probiotic-fermented blueberry juice prevents obesity and hyperglycemia in high fat diet-fed mice in association with modulating the gut microbiota. Food Funct. 2020, 11, 9192-9207. [CrossRef] [PubMed]

58. Tye, H.; Yu, C.-H.; Simms, L.A.; de Zoete, M.R.; Kim, M.L.; Zakrzewski, M.; Penington, J.S.; Harapas, C.R.; Souza-FonsecaGuimaraes, F.; Wockner, L.F.; et al. NLRP1 restricts butyrate producing commensals to exacerbate inflammatory bowel disease. Nat. Commun. 2018, 9, 3728. [CrossRef] [PubMed]

59. Wang, T.; Cai, G.; Qiu, Y.; Fei, N.; Zhang, M.; Pang, X.; Jia, W.; Cai, S.; Zhao, L. Structural segregation of gut microbiota between colorectal cancer patients and healthy volunteers. ISME J. 2012, 6, 320-329. [CrossRef] [PubMed]

60. Dayama, G.; Priya, S.; Niccum, D.E.; Khoruts, A.; Blekhman, R. Interactions between the gut microbiome and host gene regulation in cystic fibrosis. Genome Med. 2020, 12, 12. [CrossRef] [PubMed]

61. Nishitsuji, K.; Xiao, J.; Nagatomo, R.; Umemoto, H.; Morimoto, Y.; Akatsu, H.; Inoue, K.; Tsuneyama, K. Analysis of the gut microbiome and plasma short-chain fatty acid profiles in a spontaneous mouse model of metabolic syndrome. Sci. Rep. 2017, 7, 15876. [CrossRef] [PubMed]

62. Wen, L.; Wong, F.S. Dietary short-chain fatty acids protect against type 1 diabetes. Nat. Immunol. 2017, 18, 484-486. [CrossRef] [PubMed]

63. Canfora, E.E.; Jocken, J.W.; Blaak, E.E. Short-chain fatty acids in control of body weight and insulin sensitivity. Nat. Rev. Endocrinol. 2015, 11, 577-591. [CrossRef] [PubMed] 